\title{
A autonomia do Ensino Superior Português entre a lei e a prática - estudo de caso múltiplo'
}

Ana Nascimento

Belmiro Cabrito

Instituto de Educação da Universidade de Lisboa

\section{Resumo}

A autonomia no ensino superior tem tido várias interpretações. Todavia, as ideias "autonomia universitária" e "liberdade académica" sempre estiveram presentes. Neste artigo, discutem-se aqueles conceitos e contextualizam-se na atual realidade portuguesa, partindo da investigação de doutoramento em Educação intitulada "Financiamento do ensino superior público português: diversificação de fontes". $\bigcirc$ subfinanciamento público das instituições públicas de ensino superior (IES), agravado desde 1990, levou os seus dirigentes a procurar fontes alternativas de receita que, pela sua natureza privada poderão ameaçar a autonomia. A investigação pretendeu, entre outros objetivos, clarificar como os dirigentes das IES interpretam a sua autonomia considerando a dependência financeira da instituição face ao exterior. É uma investigação qualitativa, integrando-se no paradigma interpretativo-fenomenológico, assentando nas 37 entrevistas semidiretivas a dirigentes das IES da Zona Metropolitana de Lisboa e aos financiadores. Os autores concluem que os entrevistados veem diminuída a sua autonomia, nomeadamente financeira e administrativa dadas as dificuldades financeiras.

42 Palavras-chave: Educação Superior. Autonomia. Financiamento. Partilha de custos.

\section{The Autonomy of Portuguese Higher Education between law and practice - multiple case study}

\section{Abstract}

Autonomy in higher education has had several interpretations. However, the "university autonomy" and "academic freedom" have always been present. Here, authors discuss these concepts and contextualize them in current Portuguese reality, departing from a PhD research in Education: "The Portuguese higher education finance: diversifying income streams". The public underfinancing of public higher education institutions, from the 1990s onwards, has led its leaders to look for alternative revenues in the private sector, but such financing can threat higher education autonomy and academic freedom. This research intended, among other goals, to clarify how higher education leaders interpret their autonomy, considering the financial dependency of their institutions towards private sponsors. It's a qualitative research, based on 37 semi directive interviews to institutional leaders from the Lisbon Metropolitan Area and sponsors. The authors conclude that the interviewees consider that their autonomy is reduced, namely the financial and administrative autonomy due to financial difficulties.

Keywords: Higher education. Autonomy. Funding. Cost-sharing. 


\section{La autonomía de la Educación Superior en Portugal entre la ley y la prac- tica - estudio de casos múltiples}

\section{Resumen}

La autonomía universitaria ha sido interpretada de manera diferente con el tiempo mientras la "autonomía universitaria" y la "libertad académica" han sido siempre presentes. En este artículo, se analizan estes conceptos en el contexto actual de Portugal, basado en el investigación de doctorado en Educación "Financiación de la educación superior pública portuguesa: Diversificación de las fuentes". La disminución de la financiación pública de las instituciones públicas de educación superior (IES) empeorado desde 1990, llevó sus dirigentes a buscar otros ingresos que, por su naturaleza privada pueden amenazar aquellas autonomía y libertad. La investigación muestra como los líderes del IES interpretan su autonomía considerando su dependencia financiera hacia el exterior. Es una investigación cualitativa, del paradigma fenomenológico interpretativo. Fueran entrevistados 38 líderes de los IES de la zona de Lisboa y se demostró que los encuestados ven disminuidos su autonomía financiera y administrativa debido a las dificultades financieras que experimentan.

Palabras clave: Educación Superior. Autonomía. Financiación. Partilla de costos.

\section{Introdução}

Um dos desafios que se colocam, actualmente, às instituições públicas de ensino superior, é o da sua sobrevivência, tendo em atenção a queda significativa que o contributo dos orçamentos de Estado para o orçamento das instituições conheceu. De facto, os governantes, cada vez mais confrontados por solicitações de natureza social, como a educação, a saúde, a cultura, a justiça, a luta contra a pobreza ou a segurança social e face a níveis fracos de crescimento da economia, são forçados a ratear os recursos de que dispõem e, em consequência, a diminuir a sua participação na provisão daqueles serviços de natureza pública.

Nestas circunstâncias, nos últimos anos tem-se vindo a verificar uma diminuição do financiamento público das instituições públicas de ensino superior, na generalidade dos países, Portugal incluído.

Em Portugal, por exemplo, o contributo do OE para o orçamento das instituições públicas de ensino superior (universidades e institutos superiores 
A autonomia do Ensino Superior Português entre a lei e a prática - estudo de caso múltiplo

politécnicos) diminuiu, de cerca de $95 \%$, em 1995, para menos de 50\%, em 2017 (PORDATA, 2014)

Face a esta situação de subfinanciamento crónico, as instituições públicas de ensino superior têm vindo a desenvolver, por todo o mundo, políticas de diversificação de fontes de financiamento. Assim se compreende o estabelecimento de taxas de matrícula e de frequência em países onde a educação superior era, tradicionalmente, gratuita. Em Portugal, tal acontece desde 1992, com a Lei n. ${ }^{\circ}$ 20/92. Todavia, a participação dos estudantes e respectivas famílias para o financiamento das instituições públicas de ensino superior tem limites, o que leva estas instituições a procurar outras fontes de financiamento, nomeadamente fundações, associações profissionais, empresas, desenvolvendo aquilo que autores como Johnstone (2004) designa por cost sharing-partilha de custos.

Esta diversificação de fontes de financiamento tem vindo a ocorrer em Portugal desde finais da década de 1990 (CABRITO, 2002; CERDEIRA, 2009), seja através do estabelecimento de taxas de frequência actualizadas (desde 1992) seja através do aluguer de instalações e equipamentos, da prestação de serviços, de protocolos de colaboração, de investigação aplicada,

44 do mecenato, etc. $\bigcirc$ que há de comum nestas diversas fontes de financiamento é o facto de serem externas à instituição que, desse modo, porque dependente financeiramente do exterior, poderá ficar refém desses financiadores e impedida de levar a cabo a sua missão (FROELICH, 1999). Numa palavra, é possível que a autonomia e liberdade académica das instituições de ensino superior, bem como dos seus docentes, fiquem condicionadas por imposições do financiador externo.

É neste quadro de subfinanciamento crónico das instituições públicas de ensino superior que se desenvolveu a presente investigação que persegue, entre outros objectivos o de "clarificar como os dirigentes das IES interpretam a sua autonomia considerando a dependência financeira da instituição face ao exterior".

Levou-se a cabo uma investigação de natureza qualitativa, integrando-se no paradigma interpretativo-fenomenológico, tendo sido realizadas 38 entrevistas semi-diretivas a dirigentes das IES da Zona Metropolitana de Lisboa e aos financiadores externos. 
presente artigo é composto pela presente Introdução, 3 secções e

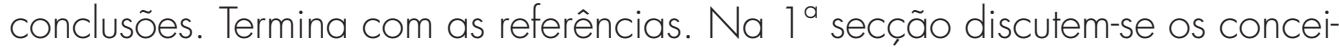
tos de autonomia e de liberdade académica apresentando-se a forma como têm sido considerados ao longo do tempo. Na secção 2 descreve-se e justifica-se a metodologia utilizada no desenvolvimento da investigação. Na secção 3, são apresentados os resultados obtidos a partir da análise de conteúdo dos protocolos das entrevistas realizadas. Termina-se o presente artigo com algumas Considerações Finais, onde se evidencia o facto de os entrevistados sentirem que têm vindo a perder autonomia administrativa e financeira em virtude da sua dependência financeira face a entidades exteriores à Academia, e com as referências.

\section{A liberdade académica e a autonomia universitária - evolução, riscos e paradoxo}

\section{Esclarecimento de conceitos?}

De acordo com Nybom (2008), o conceito de autonomia tem sido um elemento central nos debates sobre a reforma da universidade, dentro e fora da Europa, em especial, no último quarto de século. Na discussão deste conceito, as diferenças entre a universidade ideal e o que é de facto a universidade estão esbatidas, ainda que tenha existido sempre um consenso generalizado de que a autonomia institucional é fundamental para a promoção de mudanças a partir de dentro e também para garantir a liberdade académica de investigação e ensino, conceito que tem sido alvo de controvérsia, mesmo no seio da universidade (NYBOM, 2008). No texto da Magna Charta Universitatum de 1988, vem referido que a universidade é uma instituição autónoma no coração das sociedades, afirmação que tem um valor moral mas não uma força legal (NYBORG, 2003). Da mesma forma, Altbach (2001) considera que hoje em dia existe alguma confusão sobre a definição apropriada de liberdade académica, não tendo este conceito sido completamente caracterizado e não tendo adquirido a força de lei em lado nenhum. Durham (2005, p. 1) pronuncia-se no mesmo sentido ao referir que a autonomia é um valor e por isso, na maior parte das vezes, "[...] tratada como um pressuposto inerente à natureza da própria instituição". 
A autonomia do Ensino Superior Português entre a lei e a prática - estudo de caso múltiplo

Apesar de surgirem associados, os conceitos de autonomia e liberdade académica não têm o mesmo significado (BERDHAL, 1990; HENKEL, 2005) - A liberdade académica faz parte integral, aliás, de uma universidade autónoma (NYBORG, 2003) e o direito à liberdade académica é reconhecido de modo a possibilitar que docentes e alunos possam desempenhar os seus papéis (FUCHS, 1963). Para Nybom (2008) a liberdade académica refere-se às condições de trabalho dos membros individuais da universidade enquanto que autonomia refere-se ao auto governo da instituições de ensino superior (IES). Na ótica de Berdhal (1990) autonomia, no sentido literal, significa o poder de governar sem controlo externo e responsabilização significa a necessidade de demonstrar ação responsável a determinadas entidades. Teoricamente, refere, não existe incompatibilidade no facto de se ser ao mesmo tempo autónomo e responsabilizado, mas, na prática, verifica-se que o grau de autonomia diminui com o aumento das informações solicitadas. Ainda com Berdhal (1990, p. 1721, liberdade académica é a liberdade individual do académico no seu ensino e investigação para "[...] perseguir a verdade onde ela parece estar sem medo de castigo ou despedimento por ter ofendido alguma ortodoxia política, religiosa ou social". Procede ainda à distinção entre autonomia substantiva

46 - o poder da IES, na sua forma corporativa para determinar os seus objetivos e programas (o "quê" da academia), e autonomia processual - o poder da IES na sua forma corporativa para determinar os meios pelos quais os seus objetivos e programas serão alcançados (o "como" da academia), o que, no caso português, poderíamos adaptar para autonomia científico-pedagógica.

Nybom (2008) apresenta a sugestão do sociólogo alemão Stichweh (1994), do conceito de autonomia institucional, que deve incluir as seguintes dimensões: a) o direito e a competência de decidir independentemente, nos limites do compromisso institucional; b) o direito de apoiar sistemas de valores específicos e definir formas de carreira e incentivos; c) o direito de, de forma independente, decidir dos princípios institucionais e forma de governança interna; d) a possibilidade de controlar os critérios de acesso a nível de estudantes e pessoal docente; e) o direito a definir tarefas estratégicas e instituir objetivos institucionais; f) a possibilidade de identificar e determinar as relações formais e informais e ligações a outros setores da sociedade; gl o dever de responsabilidade total pelas decisões tomadas e os possíveis efeitos dessas decisões, ser "accountable" (NYBOM, 2008, p. 135). 
Considerando Ashby (1966), Berdhal (1990) acrescenta que a liberdade académica é um privilégio reconhecido internacionalmente aos professores universitários, que deve ser sempre protegido enquanto que aquilo que é autonomia não é um conceito claro e os padrões de autonomia existentes e que agradam aos académicos de várias partes do mundo são muito diversos. A esta noção acrescenta Berdhal (1990) que é necessário perceber se a intervenção do governo é em assuntos de procedimentos ou de substância. Afirma que é necessário também a negociação dos respetivos papéis, da universidade e do estado, que conduza a alguma forma de parceria e divisão de poderes. Apoiando-se ainda em Ashby (1966), Berdhal (1990) considera que a garantia da autonomia é uma definição cuidadosa dos componentes essenciais da mesma e que estes são bem entendidos por todos os intervenientes, o público, os políticos e os funcionários públicos, sendo componentes essenciais da autonomia, a liberdade para: a) selecionar pessoal e estudantes e determinar as condições em que permanecem na IES (autonomia administrativa); b) determinar currículos e graus (autonomia pedagógica); c) para alocar fundos (autonomia financeira). É importante também uma definição clara do que é a responsabilização, que itens e ações devem ser alvo de controlo, que indicadores, resultados, sanções deve a universidade apresentar, para além do aspeto financeiro que obriga a prestar contas da aplicação do dinheiro dos contribuintes. Por outro lado, Nyborg (2003) considera que a autonomia pode ser descrita como a capacidade de a IES atuar de acordo com as suas escothas na prossecução da sua missão e constitui um resultado da conjugação de vários fatores como direitos e deveres legais, recursos financeiros e outros recursos.

Considerando as reformas na governança da universidade, Christensen (2011) distingue entre autonomia formal e autonomia real. A autonomia formal pode avaliar-se, genericamente, pelo grau de autonomia real que as reformas implicaram para as universidades e é decidida a nível central (governo) e refletida em leis. Em alternativa, é possível definir o conceito de autonomia pelas suas dimensões, ou seja, as universidades podem ter vários graus de autonomia relacionados com a afiliação formal, aos sistemas de gestão, aos sistemas de financiamento, à padronização das atividades de docência e investigação. A autonomia formalé, assim, "[...] multidimensional e potencialmente hibrida, significando que as diferentes decisões podem implicar variações na centralização/descentralização ou controlo/autonomia" (CHRISTENSEN, 201 1, p. 
505) pelo que as universidades estarão sempre constrangidas por matrizes formais e existirá sempre um desvio entre o ideal e a realidade, o que leva à definição, ainda com Christensen (2011) de autonomia real e autonomia de facto (real autonomy or actual autonomy).

Note-se que, à semelhança do que se verifica com a autonomia formal, também a autonomia de facto é multidimensional, sendo ambas constrangidas pelas estruturas formais das várias dimensões da autonomia formal, mas também influenciada por fatores culturais e ambientais, e neste sentido, Durham (2005), acrescenta ainda que a autonomia é relativa porque está sujeita a constrangimentos materiais, culturais e políticos próprios da sociedade onde se insere. Por outro lado, Berdhal (1990) refere que as universidades sempre tiveram relações ambivalentes com a sociedade envolvente: tanto envolvidas como retiradas, tanto servindo como criticando, tanto a necessitar como a serem necessárias.

Mary Henkel (2005) apresenta a definição de Neave (1988) que considera autonomia académica como o direito de o pessoal do ensino superior determinar a natureza do seu trabalho, embora esta conceção tenha sido concebida quando a universidade era uma comunidade de académicos, dis-

48 tinto de um serviço público e ainda, com Baver, Marton, Askling e Marton (1999 apud HENKEL, 2005), a autonomia não é uma questão daquilo que é dado, mas é mais a extensão de como é percebida, apropriada.

\section{Ao longo da história...}

A liberdade académica, desde os tempos medievais, significou a liberdade do docente ensinar sem controlo externo na sua área de especialidade e implicava a liberdade de aprender do estudante, pois desde os primórdios, a universidade era considerada um local especial, dedicado à produção e difusão do conhecimento e, neste sentido, a universidade reclamava direitos especiais e era esperado que as autoridades seculares e eclesiásticas permitissem um grau especial de autonomia a estas instituições (ALTBACH, 200 1). No entanto, e como refere Altbach:

[...] a liberdade académica nunca foi absoluta [...] tanto o estado como a igreja exerciam algum controlo sobre aquilo que era ensinado nas universidades. Professores cujos ensinamentos entrassem 
em conflito com a Igreja Católica Romana eram por vezes sancionados e era esperada lealdade às autoridades civis $(A L T B A C H$, 2001 , p. 206).

Por outro lado, como refere Berdhal (1990) era mais fácil para um país conceder elevados graus de autonomia à academia quando apenas uma minoria de jovens a frequentava, quando as disciplinas se limitavam ao "trivium e quadrivium" (BERDHAL, 1990, p. 171) e praticamente sem fundos do estado.

A universidade moderna, que nasceu, associada às reformas de Humboldt na Prússia e Napoleão em França (AMARAL; MAGALHÃES, 2000), no final do século XIX, foi um instrumento fundamental na construção e reforço do estado-nação, garantindo a formação dos altos quadros do estado, a socialização e mobilidade dos alunos nos futuros empregos. Assim, nesta altura, o estado era o único regulador do sistema, existia uma centralização elevada e que podia ir até à definição dos currículos, dado que o estado era o principal empregador dos estudantes das universidades sendo, ao mesmo tempo, defensor da interferência de interesses estranhos à academia (AMARAL; MAGALHÃES, 2000). Na universidade alemã, com Humboldt, a liberdade académica expandiu-se enquanto conceito e a investigação passou a figurar na missão académica (ALTBACH, 2001); o conhecimento e a sua institucionalização foram colocados no centro da universidade, já não mais sobre as tutelas da lgreja, do estado (com algumas restrições) e outros interesses, estando a liberdade académica centrada nos indivíduos académicos e não na instituição (AMARAL; MAGALHÃES, 2000). O modelo napoleónico era mais restritivo em relação à liberdade académica, embora não seja incompatível com o modelo humboldtiano pois, como referem Amaral e Magalhães (2000), ambos os modelos partilham a consciência da necessidade de proteger a universidade contra influências estranhas.

Como refere Nybom (2008), a universidade esteve sempre ligada a vários sistemas de responsabilização social, eclesiástica, monárquica, cívica e estas ligações seriam determinantes na conceção da autonomia futura, uma vez que,

[... ] a autonomia é sempre historicamente situada e tem de ser entendida como uma dimensão relativa com um impacto crucial no modo como o ensino superior e a investigação funcionam realmente num 
A autonomia do Ensino Superior Português entre a lei e a prática - estudo de caso múltiplo

conjunto de circunstâncias históricas e sociais (NYBOM, 2008, p. 1351 .

Do exposto percebe-se bem que sempre existiram limites à autonomia da universidade que nunca foi, realmente, autónoma.

Entretanto, e à semelhança do que acontecia no resto da Europa, a universidade portuguesa respondia aos desígnios da igreja, mantendo os sistemas de ensino e os conteúdos numa grande homogeneidade (GOMES, 2004). A Reforma do Marquês de Pombal (1772) e as reformas de Passos de Manuel (1837) tiveram como objetivo dotar o país de um sistema de ensino que a abolição das ordens religiosas tinha destruído, tendo sido criadas as Escolas politécnicas de Lisboa e do Porto, que seriam a semente das futuras universidades (GOMES, 2004).

De acordo com Santos (1999), as universidades de Coimbra, Lisboa e Porto, possuíam, desde 1952, um regime de autonomia com um elevado grau de descentralização interna: a administração das universidades competia aos senados e a das faculdades e escolas não integradas competia aos conseIhos escolares. O Decreto-Lei n 38.692, de 21 de março de 1952, retira essa

50 autonomia administrativa às unidades orgânicas e estabelecimentos anexos, centralizando a administração num conselho administrativo de universidade, com gozo de uma autonomia administrativa fortemente condicionada pela lei geral. A justificação para a adoção destas medidas foi o facto de nem os senados, na universidade, nem os conselhos escolares, nas escolas, assumirem ou exercerem as competências administrativas que a lei thes consignava, não fazendo qualquer uso dessa autonomia.

Em 1973, o então Ministro da Educação do Governo de Marcelo Caetano, último governo da ditadura em Portugal, José Veiga Simão, elaborou um projeto de reforma do ensino, que se designou por Reforma Veiga Simão, onde as universidades novas, criadas pelo Decreto-Lei n ${ }^{\circ}$ 402, de 11 de agosto de 1973, são dotadas de autonomia administrativa e financeira, sendo a respetiva estrutura e a orgânica pedagógica e administrativa das unidades de ensino e de investigação remetidas para um diploma, o Projecto de Diploma Orientador do Ensino Superior, que acabou por ser aprovado pelo Ministro Veiga Simão em 16 de Abril de 1974.

Desse Projecto destacamos o artigo 13, que postula que as universidades têm "[...] personalidade jurídica e património próprio e dispõem de 
autonomia pedagógica, científica e cultural, administrativa e financeira, e disciplinar, sem outras limitações além das estabelecidas por lei". A Revolução Democrática de 25 de Abril de 1974 suspendeu o processo de reforma então iniciado. Após a Revolução e a retoma da democracia, é publicada a Constituição da República Portuguesa (CRP - 1976) mas, de acordo com Veiga Simão (2003) a autonomia da universidade seria explicitada pela primeira vez na revisão de 1982 da CRP, no art. $76^{\circ}$ cujo n 2 refere que as universidades gozam de autonomia científica, pedagógica, administrativa e financeira, nos termos da lei. Posteriormente a revisão de 1989 da CRP acrescenta outra dimensão da autonomia, a da autonomia estatutária (art. 76\%) e depois, a revisão constitucional de 1997, acrescenta a estas autonomias, " [...] sem prejuízo de adequada avaliação da qualidade do ensino" (SIMÃO, 2003, p. 14), considerando Simão (2003) que esta nova dimensão de avaliação marca o início de uma nova relação entre a universidade e o estado, tornando a autonomia mais responsabilizante. Inspirada na CRP de 1976, a lei da Autonomia das Universidades (Lei n. ${ }^{\circ}$ 108, de 24 de outubro de 1988), define a natureza jurídica da universidade (art. $3^{\circ}$ ) como (1) "[...] pessoas coletivas de direito público e gozam de autonomia estatutária, científica, pedagógica, administrativa, financeira e disciplinar", muito semelhante ao texto da revisão da CRP de 1989. Em relação às autonomias, a lei da Autonomia das Universidades especifica as dimensões das diferentes autonomias:

- Artigo $6^{\circ}$ Autonomia científica

A autonomia científica permite às universidades a capacidade de definir, programar e executar a investigação, atividades científicas e culturais, a realização de ações comuns com outras entidades públicas ou privadas, nacionais ou estrangeiras, devendo estas ações e programas ser compatíveis com a natureza e os fins da universidade e ter em conta as grandes linhas da política nacional, designadamente em matérias de educação, ciência e cultura e relações internacionais.

\section{- Artigo To Autonomia pedagógica}

Esta autonomia confere às universidades, em harmonia com o planeamento das políticas nacionais de educação, ciência e cultura, a faculdade de criação, suspensão e extinção de cursos, na elaboração dos planos de estudo e programas das disciplinas, definição dos métodos de ensino, escolha dos 
A autonomia do Ensino Superior Português entre a lei e a prática - estudo de caso múltiplo

processos de avaliação de conhecimentos e ensaio de novas experiências pedagógicas, assegurar a pluralidade de doutrinas e métodos que garanta a liberdade de ensinar e aprender. Os problemas específicos do ensino médico são alvo de legislação especial.

- Artigo $8^{\circ}$ Autonomia administrativa e financeira

A autonomia administrativa é exercida no quadro da legislação geral aplicável, estando as universidades dispensadas de visto prévio do Tribunal de Contas, exceto nos casos de recrutamento de pessoal com vínculo à função pública. Em relação à autonomia financeira, as universidades dispõem do seu património, sem outras limitações além das legais, gerem livremente as verbas anuais atribuídas nos orçamentos do Estado, capacidade de transferir verbas entre as diferentes rubricas e capítulos orçamentais, elaboram os seus programas plurianuais, capacidade para obter receitas próprias a gerir anualmente através de orçamentos privativos, conforme critérios por si estabelecidos, e podem arrendar diretamente edifícios indispensáveis ao seu funcionamento.

- Artigo $9^{\circ}$ Autonomia disciplinar

52 As universidades dispõem do poder de punição, infrações disciplinares praticadas por docentes, investigadores e outros funcionários, devendo o regime disciplinar aplicável aos estudantes ser definido por lei, sob proposta do Conselho de Reitores, ouvidas as estruturas representativas dos estudantes e as penas têm sempre direito de recurso, nos termos da lei.

Para o exercício destas autonomias, a Lei da Autonomia Universitária estabelece, no Art. 15\%, os meios necessários ao seu exercício postulando que cada universidade deve dispor dos meios humanos e técnicos necessários ao exercício da autonomia, cabendo às universidades o recrutamento e promoção dos seus docentes e investigadores e restante pessoal, podendo contratar, em termos a definir por lei e nos respetivos estatutos, individualidades nacionais e estrangeiras para o exercício de funções docentes ou de investigação e outro pessoal para o desempenho de atividades necessárias ao seu funcionamento. Alerta, todavia, que estas contratações não conferem, em caso algum, a qualidade de funcionário público ou de agente administrativo, ainda que tendo em atenção o disposto no $n^{\circ} 5$ do mesmo artigo, as universidades e as unidades orgânicas dotadas de autonomia podem alterar os quadros de pessoal, desde que tal alteração não se traduza em aumento dos valores monetários totais 
globais. Se existirem aumentos quantitativos globais estes quadros são revistos e carecem de aprovação governamental.

Esta lei não faz qualquer menção ao ensino superior politécnico, ainda que a Lei de Bases do Sistema Educativo de 1986 (Lei 46, de 14 de outubro de 1986) consagre a sua existência, instituindo formalmente o Sistema Binário. que consta na Lei da Autonomia é uma menção no art. $3^{\circ}$, à natureza jurídica dos estabelecimentos de ensino superior universitário não integrados em universidades, onde são aplicados os mesmos princípios e as regras de autonomia relativos às universidades e estabelecimentos equivalentes. Postula ainda que estes estatutos devem ser aprovados pelo ministro da tutela, e que estas instituições devem adaptar às suas condições específicas as normas gerais definidas, nomeadamente as relativas aos órgãos de governo da universidade e as que dizem respeito à concessão de títulos e graus.

\section{$[\ldots]$ até aos dias de hoje $[\ldots]$ que autonomia $(\mathbf{s})$ ?}

Como refere Nyborg (2003, p. 2), até há cerca de duas décadas, as universidades, na maioria dos países europeus, eram elementos num "sistema de instituições de estado", seguindo as mesmas regras. As leis relativas às universidades geralmente consideravam-nas um tipo especial de instituição estatal, com direito a autogoverno, geralmente com um reitor eleito e um senado académico a governar a IES, e locais onde a liberdade académica seria respeitada, sendo que esta liberdade "[...] estava principalmente relacionada com assuntos académicos, não a assuntos económicos e assuntos organizacionais" (NYBORG, 2003, p. 2). Esta situação alterou-se e atualmente, as IES podem ter maior liberdade económica, organizar-se em companhias ou fundações para conseguirem uma maior flexibilidade relativamente ao aparato legislativo do estado, mas atualmente em muitas situações, os órgãos de governo são formados por individualidades de fora da academia e por isso, a comunidade académica já não governa a universidade sozinha (NYBORG, 2003). Aliás, Henkel (2005) refere que a universidade é uma comunidade de académicos, um serviço público e muitas vezes um negócio, publicamente responsável perante o estado e responde a inúmeros mercados e os académicos e as IES têm de aceitar integrar direitos competitivos e aceitar mais obrigações, trabalharem com regras e avaliações definidas externamente, responderem 
A autonomia do Ensino Superior Português entre a lei e a prática - estudo de caso múltiplo

pelo financiamento e pela qualidade científica, tendo assim, ocorrido uma "deriva epistémica" (ELZINGA, 1985 apud HENKEL, 2005) da universidade.

Em Portugal, atualmente, e através da Lei n. ${ }^{\circ} 62$, de 10 de setembro de 2007 (Regime Jurídico das Instituições de Ensino Superior), a autonomia das IES é considerada no artigo $11^{\circ}$, onde é referido que estas instituições gozam de autonomia estatutária, pedagógica, científica, cultural, administrativa, financeira, patrimonial e disciplinar face ao estado e à entidade instituidora. Cada IES tem estatutos próprios onde são enunciados os objetivos pedagógicos e científicos e concretizam a sua autonomia e definem a estrutura orgânica. Todavia, refere-se ainda que esta autonomia não impede a fiscalização nem a avaliação interna e externa, registando-se assim a introdução de mais regulação na avaliação e maior responsabilização, aprofundando esta nova relação universidade-estado, descrita por Simão (2003) anteriormente. A autonomia académica é consagrada no capítulo III e refere-se a seis tipos de autonomia: a) autonomia na definição da missão (art. 70\%) 1) cabe a cada uma das IES públicas, a definição dos seus objetivos e seu programa de ensino e investigação de acordo com a sua vocação e recursos disponíveis, 2) é competência de cada IES a criação, transformação ou extinção de unidades orgânicas e de 54 ciclos de estudo, sendo necessária a homologação; b) autonomia académica (art. $71^{\circ}$ ) 1 e 2) as IES gozam de autonomia cultural, científica, pedagógica e disciplinar e as escolas e unidades de investigação gozam, designadamente de autonomia científica e pedagógica, nos termos estatutários da instituição a que pertencem; c) autonomia cultural (art. $72^{\circ}$ ) capacidade de definição do programa de formação e iniciativas culturais; d) autonomia científica (art. 73\%), a capacidade de definir, programar, executar investigação e outras atividades científicas, sem prejuízo dos critérios de financiamento público da investigação; e) autonomia pedagógica (art. $74^{\circ}$ ) capacidade de elaboração dos planos de estudo, definição do objeto das unidades curriculares, métodos de ensino, afetação de recursos e escolha dos processos de avaliação e, finalmente, f) autonomia disciplinar (art. $75^{\circ}$ ) referente à capacidade das IES de aplicar sanções disciplinares, de acordo com o código do trabalho e com o estatuto dos funcionários e dos estudantes e pertence ao reitor ou ao presidente, conforme os casos.

No capítulo $V$, dedicado à gestão patrimonial, administrativa e financeira é referido, no art. $108^{\circ}$ que as IES públicas gozam de autonomia patrimonial, administrativa e financeira nos termos da lei e, especificamente 
na autonomia financeira, é referido, no art. $111^{\circ}, 1$ ) que as IES podem gerir livremente os seus recursos financeiros, conforme critérios por si estabelecidos, incluindo as verbas anvais atribuídas via orçamento de estado e no âmbito desta autonomia 2) a) elaboram planos plurianuais; b) elaboram e executam os seus orçamentos; c) liquidam e cobram as receitas próprias; d) autorizam despesas e efetuam pagamentos; e) procedem a todas as alterações orçamentais, com exceção das que sejam competência da Assembleia da República e das que não sejam compatíveis com a afetação de receitas consignadas. $\bigcirc$ artigo $115^{\circ}$ refere que constituem receitas das IES, além das dotações do orçamento do estado e das propinas (taxas de frequência), das receitas de financiamento provenientes de contratos de financiamento plurianual com o estado, as receitas provenientes de atividades de investigação e desenvolvimento, rendimentos da propriedade intelectual, rendimentos de bens próprios ou de que tenham fruição, receitas derivadas da prestação de serviços, emissão de pareceres e da venda de publicações e de outros produtos da sua atividade, subsídios, subvenções, comparticipações, heranças e legados, o produto da venda ou arrendamento de bens imóveis e de outros bens, quando autorizada legalmente, os juros de contas de depósitos e a remuneração de outras aplicações financeiras, os saldos de conta de gerência de anos anteriores, o produto das taxas, emolumentos, multas, coimas e outras receitas que legalmente lhes advenham, o produto de empréstimos contraídos e outras previstas por lei.

A propósito da liberdade académica, no RJIES afirma-se no art. $137^{\circ}$ que, em situações de crise que não possam ser superadas no quadro da autonomia regulada, o governo pode intervir na instituição, pode suspender os órgãos estatutários e nomear uma personalidade independente para o governo da IES durante o tempo necessário à normalização do governo da instituição, mas que esta intervenção não pode pôr em causa a liberdade académica nem a liberdade de ensinar e aprender dentro da instituição. Outra referência no art. $142^{\circ}$, responsabilidade das $\mathbb{I E S}$, onde refere que estas instituições são patrimonialmente responsáveis por danos causados a terceiros por titulares de órgãos ou outros agentes, sem prejuízo da liberdade académica.

\section{Os riscos... e o paradoxo da autonomia}

De acordo com Altbach (2001), a força relativa da liberdade académica nos países mais industrializados é, de alguma forma, consensual, 
A autonomia do Ensino Superior Português entre a lei e a prática - estudo de caso múltiplo

havendo países em que a liberdade académica é posta em causa, em vários graus, especialmente em países com regimes ditatoriais, levando Karran (2007) a afirmar que quando a liberdade académica é variável entre países, a probabilidade de mobilidade é reduzida, uma vez que é pouco provável que alguém vá para um país onde a sua liberdade de expressão e investigação seja cerceada.

Neste sentido, a utilização crescente das novas tecnologias de informação e comunicação pode constituir uma ameaça nas trocas de cursos online e de informação entre países com graus díspares de liberdade académica (KARRAN, 2007). No entanto, apesar da "situação saudável" (ALTBACH, 2001 , p. 215) em termos de liberdade académica que se vive no contexto dos países mais desenvolvidos e industrializados, é necessário ter alguma atenção. Assim, por exemplo, nos EUA, existe o debate de que a maior ameaça à academia vem de dentro da própria academia, no sentido de haver algum excesso de politização em algumas IES, onde pontos de vista divergentes não são muito bem vistos. Outros autores consideram que o envolvimento crescente das empresas na universidade e o aumento de patrocinadores privados a nível da investigação condiciona a autonomia (SLAUGHTER; LESLIE, 1997 apud

56 ALTBACH, 2001) e que a dependência externa de financiamento também pode condicionar a autonomia (GIBB; HASKINS; ROBERTSON, 2013) já que, se para alguns autores o financiamento pelo estado limita a liberdade académica (LICHUAN, 2004 apud GIBB; HASKINS; ROBERTSON, 2013), para outros a procura de fontes externas sabota a autonomia tradicional, relacionada com a segurança do financiamento público e do estado que protege as universidades de influências estranhas (CHRISTENSEN, 2011 ). Para outros ainda, fontes de financiamento extragovernamentais, principalmente quando oriundas do setor privado, têm muitas vezes interesses associados (LESLIE; RAMEY, 1998 apud GIBB; HASKINS; ROBERTSON, 2013) que podem induzir as universidades noutro sentido que não o da sua missão particular (HEARN, 2003 apud GIBB; HASKINS; ROBERTSON, 2013) ou levar a um deslocamento da sua missão (FROELICH, 1999).

funcionamento e a autonomia das IES são, pois, condicionados pelo financiamento apesar de, como refere Cabrito (1999; 2002), o financiamento não ser um fim em si mesmo. Existe uma relação entre a modalidade de financiamento e a autonomia apresentada por Williams ( 1990 apud CABRITO, 1999) onde é feito um inventário das modalidades de financiamento das IES, 
relacionadas com as formas de organização e de tomada de decisão possíveis. A importância destes modelos e modalidades de financiamento reside no facto de possibilitarem análises e comparações e pelo facto de darem a conhecer o contexto em que ocorrem as políticas financeiras e orçamentais e, assim, contribuírem para reconduzir ou reconstruir essas políticas (CABRITO, 1999; 2002). Em relação ao caso português, Cerdeira (1999 apud CERDEIRA, 2009) refere que o grau de autonomia das IES se encontra relacionado com a estrutura de financiamento. Ou seja, quando existe só uma ou poucas entidades financiadoras, tal facto limita a independência das IES. Desta forma, considera a autora que o facto de o Estado ser o principal financiador do sistema de ensino superior público português, tem consequências na gestão praticada nas IES, um funcionamento mais conservador e administrativo, em lugar de existir uma gestão mais moderna e flexível, que iria de encontro às aspirações dos académicos e, provavelmente, do governo e da sociedade (CERDEIRA, 1999 apud CERDEIRA, 2009).

Outra questão que pode condicionar a autonomia, conforme Altbach (2001) são as novas tendências de gestão das universidades, por vezes designada managerialism (ALTBACH, 2001), inspiradas no New Public Management (NYBOM, 2008), em que há um aumento de poder de administradores e outras entidades, distintas da autoridade dos docentes no governo da academia e esta transferência de poder e autoridade vai afetar o papel tradicional da profissão de docente universitário, com consequências na liberdade académica, levando o autor a concluir que os "[...] desafios à liberdade académica nos países industrializados são mais subtis, e talvez de certa forma mais danosos de que as violações mais abertas" (ALTBACH, 2001, p. 217) como as que existem em países com liberdade limitada.

A propósito destas novas tendências de governança da universidade, atualmente e de uma forma geral, a nível europeu, o conceito de autonomia é definido e utilizado quase somente com um sentido técnico e instrumental (NYBOM, 2008, p. 136), apresentada como uma ferramenta operacional "[...] promovida e aceite pelo estado como o melhor meio prático para gerir eficientemente o "negócio universitário»", levando a que o grau de responsabilização (accountability) perante a sociedade e o estado seja cada vez maior, geralmente apropriado e traduzido numa fórmula técnica, com indicadores quantitativos rígidos, tendo a autonomia apenas uma dimensão de gestão. Neste sentido, os apelos políticos dos líderes europeus no sentido de maior 
A autonomia do Ensino Superior Português entre a lei e a prática - estudo de caso múltiplo

autonomia das universidades não têm nada a ver com a liberdade académica (NYBOM, 2008). Alegadamente, esta autonomia reforça a capacidade de as universidades responderem rápida e eficientemente às exigências da sociedade mas, as consequências desta maior autonomia são uma "[...] abundância de responsabilização e de esquemas de avaliação expost, contratos de curto prazo e por tarefas e distribuição de financiamento baseada na performance" (NYBOM, 2008, p. 137). Ou seja, ainda com Nybom (2008) este movimento de aumento de autonomia a partir de fora pode ser uma forma de aumentar a dependência política e

[...] enquanto é dado maior poder de decisão às universidades o poder de decisão, a sociedade tenta cada vez mais, através de diferentes mecanismos e dispositivos, impor as suas exigências, visões, interesses e valores nas políticas de longo prazo das universidades e nas prioridades de curto prazo (NYBOM, 2008. p. 137).

Christensen (2011) pronuncia-se no mesmo sentido quando refere que o aumento na autonomia é contraposto por um aumento de instrumentos de controlo, combinando regulação e desregulação, o que leva este autor a considerar que parece existir um "paradoxo na autonomia" (CHRISTENSEN 2011 , p. 515) dado que as modernas reformas na universidade mudaram o sistema de uma "[...] autonomia formal baixa e uma autonomia real alta, para uma situação de autonomia formal elevada mas uma baixa autonomia real" e ainda com Berdhal (1990), em teoria parece não haver incompatibilidade entre ser-se ao mesmo tempo altamente autónomo e responsabilizado mas, na prática, sente-se que "[...] geralmente onde muita responsabilização é requerida, menos autonomia resta" (BERDHAL, 1990, p. 171).

Neste quadro, como se encontra a academia, em Portugal? Numa situação de procura incessante de fontes externas de financiamento que colmatem ou combatam a diminuição do contributo financeiro do estado para o ensino superior público dos últimos anos, perceber as consequências dessa procura nas múltiplas autonomias das instituições de ensino superior surge como indispensável e foi um dos objetivos da pesquisa levada a cabo e da qual, de seguida, se apresenta a metodologia utilizada e alguns resultados preliminares. 


\section{Metodologiao}

Para compreender a política de diversificação das fontes de financiamento das instituições públicas de ensino superior portuguesas, esta investigação pretendeu clarificar de que forma os dirigentes dessas instituições Imembros dos conselhos gerais/reitores/presidentes/diretores das unidades orgânicas) interpretam a autonomia universitária e procuram fontes alternativas de financiamento, no mundo empresarial ou da filantropia.

$\bigcirc$ ponto de partida da investigação foi perceber qual o papel que a diversificação das fontes de financiamento poderá desempenhar no futuro do ensino superior português. Este objetivo geral foi acompanhado de objetivos específicos, nomeadamente, entre outros: a) medir o contributo de cada fonte de financiamento no orçamento total das instituições; b) a forma de utilização desse financiamento; e, c) analisar o modo como as instituições gerem a sua autonomia num quadro de "abertura" ao financiamento externo.

Foram escolhidas as IES da Área Metropolitana de Lisboa, devido a três fatores: a) o elevado número de IES existentes nesta área - duas Universidades (Universidade de Lisboa e Universidade Nova de Lisboa), dois Institutos superiores politécnicos (Lisboa e Setúbal) e um Instituto Universitário - (ISCTE; b) é a região com maior peso no total da população nacional - $26 \%$ do total nacional (INE - Censos 2011 ); c) o número de alunos inscritos no ensino superior público é o mais elevado (150.669, num total de 403.445 - cerca de 37\% do total de alunos, GPEARI, 20111 .

A investigação decorreu em três momentos distintos. Numa primeira fase procedeu-se a uma pesquisa documental sobre o tema, no sentido de enquadrar a experiência das instituições estudadas nas tendências nacionais, europeias e mundiais. Num segundo momento utilizou-se a abordagem de estudo de caso múltiplos (MORGADO, 2012) ou coletivos (STAKE, 1999 apud MORGADO, 201 2), utilizados quando o investigador pretende estudar mais do que um contexto, sujeito ou situação simultaneamente, embora com o mesmo objeto de estudo e onde as conclusões obtidas se referem a um contexto mais abrangente e podem assumir uma grande variedade de formas (BOGDAN; BIKLEN, 1994).

Nesta investigação cada IES correspondeu a um caso e para explorar cada um foi utilizada uma abordagem qualitativa, através da realização de 
entrevistas semi-diretivas ou semiestruturadas, que deram várias perspetivas dos casos uma vez que a "[...] entrevista é a via principal para as realidades múltiplas" (STAKE, 2007, p. 81). Foram realizadas 37 entrevistas, 34 das quais a diretores e presidentes das IES, diretores financeiros, membros e presidentes do Conselho Geral. As três restantes foram realizadas junto de financiadores/ patrocinadores, duas entidades bancárias, em que os entrevistados estavam a cargo da relação do banco com a universidade, e uma Fundação que dá bolsas aos estudantes. Após as entrevistas aos sujeitos do estudo, foi possível ter conhecimento de quem são os financiadores e entrevistá-los, o que permitiu perceber as razões subjacentes a esses financiamentos, os objetivos específicos desta forma de "ajuda", as razões que explicam terem optado pelo financiamento de determinada instituição em detrimento de outras e as possíveis exigências colocadas, às instituições financiadas.

As entrevistas foram objeto de análise de conteúdo, na linha de Bardin (1976) e foi feita uma triangulação (STAKE, 2007) dos dados recolhidos. Finalmente, num terceiro momento e após a triangulação entre as entrevistas e a análise documental, proceder-se-á à redação do relatório final, fase presentemente em curso.

\section{Resultados}

Para o presente artigo, apenas foram considerados os resultados relativos à autonomia das IES, ao estado da autonomia do ensino superior público em Portugal, aos fatores enunciados pelos entrevistados que limitam a autonomia e a algumas críticas feitas aos documentos legais e às práticas do estado por parte deles.

De salientar, ainda, que durante o período do estudo, Portugal encontrava-se ao abrigo da lei de contenção orçamental, com uma conjuntura de crise económica e financeira que exigiu um pedido de empréstimo pelo Estado português ao FMI e ao BCE, acompanhado de um programa de ajustamento estrutural caracterizado por políticas de austeridade. 


\section{O estado da autonomia na visão dos entrevistados}

Para os entrevistados a autonomia é essencial e é um elemento indispensável ao funcionamento das IES,

[...] e isso consegue-se... evitando a governamentalização e a partidarização das instituições que têm que ser independentes... mas têm que ter capacidade para realizar a sua política e depois prestar contas, porque são instituições de serviço público [...] (F2, 20151.

A consciência da necessidade de responsabilização nas palavras deste entrevistado, posição partilhada com a maioria dos sujeitos do estudo.

Para um dos entrevistados, a universidade nunca foi completamente autónoma dos poderes centrais e para outro, a autonomia que existe "[...] é uma autonomia regulada... No ensino superior, há alguma autonomia [...]" (F15, 2015).

No entanto, para quase todos os entrevistados, neste momento, a autonomia está limitada, cerceada e consideram que deveria haver mais autonomia. Uma das razões são os cortes no financiamento. Em relação aos Institutos Superiores Politécnicos, uma vez que a grande maioria das escolas não têm autonomia financeira, alguns entrevistados entendem e concordam com a centralização, mas gostariam de ter mais liberdade de movimentos na gestão corrente do orçamento:

[...] gostava de ter mais autonomia nomeadamente para as pequenas despesas e para coisas que considero necessárias sem ter que estar sempre a pedir para ser cabimentado, para ser autorizado, pede-se uma proposta, é feita aqui no papel, demora um dia a chegar ao departamento, DFAP e é assinado pela subdiretora, depois vem ser autorizada por mim e só depois é que pode ser paga passado um mês, é muita burocracia para mim [...] (IP1, 2015).

Por outro lado, consideram que devem ter condições para exercício da autonomia, mas o Estado dificulta, apresentando atitudes como a que refere um entrevistado:

[...] até prova em contrário, os dirigentes são aparentemente criminosos e isso parece-me um disparate. [...] Portanto, concordo 
A autonomia do Ensino Superior Português entre a lei e a prática - estudo de caso múltiplo

absolutamente com as autonomias mas deve ser uma autonomia com respeito pelas pessoas e com liberdade, para que a pessoa possa inovar, crescer, criar, sem todos esses constrangimentos... sem ter que demonstrar a cada instante que não sou criminoso [...] (IP10, 2013).

\section{Os constrangimentos à autonomia}

De uma forma geral, os entrevistados focaram os seguintes aspetos como entraves à autonomia:

a) Legislação e normas legais - Consideram que, com tanta legislação, a autonomia está cada vez mais posta em questão, que é uma autonomia relativa, uma vez que as regras vêm do poder central. Alguns entrevistados referem o facto de o ensino superior não ter incumprido na dívida face ao exterior, o que originou o pedido de empréstimo a instâncias internacionais, pelo que é incompreensível que estas instituições sejam postas em causa por órgãos da tutela:

[temos que nos] submeter ao espartilho e à câmara de uma legislação que é imensa, repetida, incongruente, contraditória e nós estamos aqui sempre com medo, viola aquilo, viola isto, não pode ir para aqui, não pode ir para a frente, não pode ir para trás [...] Nós temos hoje orçamentos pequenos e quando estamos a pensar em gastar o dinheiro, se tivéssemos um bocadinho mais de liberdade e as chamadas leis da contabilidade pública, esse espartilho legal, se não estivesse tão presente, nós prestaríamos contas, em auditorias, em fiscalizações, etc. porque o que está, está [...] (F5, 20131.

[a autonomia] Acho que é fortemente atingida com muita frequência, fortemente limitada frequentemente pelo estado, particularmente pelo Ministério das Finanças. Tenho competências, os presidentes dos politécnicos têm competências, os reitores, que frequentemente são violadas, atingidas por normas, decisões que vêm das Finanças, que são omnipresentes e omnipotentes, podem tudo e atingem a autonomia... era preferível termos menos financiamento e mais autonomia, acho que as instituições se veem muitas vezes coartadas na sua capacidade porque estão constantemente a ser atingidas no bem mais precioso que têm que é a autonomia $[\ldots](I P 11,2013)$. 
Consideram que "[...] o RJIES tinha que nos libertar disto, tínhamos que ter muito mais autonomia. Nós não contribuímos para o défice. Se todas as entidades públicas ... fossem como as universidades, não tínhamos défice $[\ldots]^{\prime \prime}(F 5,2013)$;

b) Contratação de pessoal - os entrevistados consideram que não têm autonomia para contratar o pessoal académico que pretendem, uma vez que têm que obedecer às regras de contratação da Administração Pública: "[... n não tenho autonomia para escolher os recursos humanos e uma política de promoções interna $[\ldots]^{\prime \prime}(\mathrm{F} 10,2014)$

E, por outro lado, a bolsa de emprego do estado, no quadro do programa de mobilidade da função pública, limita a escolha de pessoal ao que existe na base de dados, que, por vezes, não é adequado ao perfil pretendido, uma vez que esta bolsa efetua:

[...] reaproveitamento dos professores que exercem funções públicas e de não poder abrir concurso ao exterior para recrutar pessoas. Percebo que a administração pública tem gente a mais... Mas quando abro um concurso... na bolsa de emprego público uma necessidade que tenho de um colaborador e não me responde ninguém à altura do perfil que eu preciso, acho que se não há, não vou fabricar, deveria poder ir ao mercado, entraria só alguém que correspondesse ao perfil, porque este aperto de não poder entrar, claro que sei que há a norma de exceção... (F14, 2014).

c) Limitação nas compras - Alguns entrevistados referem em específico os entraves à autonomia causados pelos procedimentos burocráticos, nomeadamente a nível da aquisição de materiais e da necessidade de terem que se fazer compras através da Agência Nacional de Compras:

[...] estou a comprar coisas com uma qualidade pior e mais caras algumas do que se fosse ao mercado. Para comprar um computador para investigação ou outro computador qualquer tenho que pedir licença, tenho que pedir uma exceção que demora 3 meses e a atividade de investigação não se coaduna com 3 meses de espera $[\ldots](F 12,2013)$.

[...] A autonomia, como está, julgo que não há necessidade, nunca me senti preso, é querer gastar aqui ou acolá e não poder. $\mathrm{Na}$ verdade, temos restrições, temos regras, se me passassem uma informação do género, autonomia financeira poderá ser por 
A autonomia do Ensino Superior Português entre a lei e a prática - estudo de caso múltiplo

exemplo eu comprar equipamentos onde são mais baratos, aí gostava. Porque muitas vezes sou obrigado a comprar equipamentos muito mais caros só porque não posso comprar onde é mais barato, é ridículo, mas é verdade. Mas isso não é da autonomia nem minha nem do IP porque o IP é obrigado a cumprir as regras da função pública [...] (IP6, 2014).

d) Gestão e utilização das receitas próprias - os entrevistados referem que o enquadramento da administração não é justo, pois trata as instituições todas por igual, mesmo as que não contribuíram para o défice como as IES e as impede de gastar as receitas próprias como desejam:

[...] a administração pública é tomada como um centro de custo, em geral, esta escola não é um centro de custo, esta escola é um caso, se calhar atípico na universidade de Lisboa [...] os casos atípicos deveriam ser considerados porque se tomam todos como gastadores, maus zeladores dos dinheiros públicos, etc. [...] as regras que me são aplicadas, são aplicadas como aqueles que incumpriram, gastaram muito, se endividaram, fizeram tudo mal, pronto. Quem fez mal, é-he aplicado um pacote, quem fez bem, é-lhe aplicado o mesmo pacote, por isso isto é uma situação confrangedora que é eu gerar saldos que tenho dificuldade em usar os saldos $[\ldots](\mathrm{F} 10,2014)$.

[...] queremos gastar essas receitas próprias como nos convier, não podemos. Temos de gastar [...] conforme gastamos o $O E[\ldots]$ deixem-nos gastar como queremos [...] mais laboratórios, contratava investigadores, ia buscar equipas ao estrangeiro para fazer investigação aqui e euisto precisávamos de ter alguma autonomia para gerir esse dinheiro e não temos [...] o dinheiro vem e temos que gastá-lo ov executá-lo nos termos das regras da administração pública [...] (F14, 2014).

e) Falta de recursos financeiros e outros - os entrevistados referem principalmente a escassez do financiamento como um entrave ao exercício da autonomia.

Na ótica dos entrevistados, o subfinanciamento e a existência de um orçamento anual ao invés de plurianual:

[...] limita profundamente a capacidade de autonomia. Porque o que é o exercício autónomo da governação por uma instituição é ter a capacidade de escolher e fasear essas escolhas no tempo, adequá-las no tempo... devíamos de ter a capacidade de ter 
planos e orçamentos plurianuais... ainda estamos muito dominados pela necessidade do financiamento para o funcionamento normal, temos muito pouca margem de manobra [...] (F2, 2015).

Neste sentido, um entrevistado refere que preferia ter menos financiamento, mas mais autonomia. Outro refere que vê a autonomia com contratualização, as IES são financiadas e devem responder pelos indicadores, mas esses indicadores parecem não existir:

[... ninguém nos diz se estamos a fazer bem ou mal, a única coisa que nos dizem é vais ter lá menos dinheiro, como sabem, a conjuntura, estes problemas, menos $5 \%$, menos $10 \%$ é a única mensagem e com isto não se diz nem bem nem mal, é só isso. Se gerir muito bem a instituição levo 5\% de corte, se gerir muito mal levo 5\% de corte. São essas diretivas, quando não há dinheiro, o mal reparte-se por todos... nunca ouvi um indicador do que quer que seja, estamos preocupados com o que um e outro faz, mas indicadores do financiador mor? zero, haja mais ou menos dinheiro [...] (IP 13, 2014).

Um dos entrevistados considera que não tem autonomia, nem sabe muito bem se tem autonomia pedagógica, pois queria ter liberdade de escolher a agência acreditadora, que não tem autonomia administrativa e que a financeira é muito pequena. Outro entrevistado considera que somente se pode falar em autonomia universitária se houver "[...] autonomia financeira e administrativa e essa é que permite depois salvaguardar a visão e a missão da universidade $[\ldots]^{\prime \prime}(F 7,2014)$.

Por outro lado, outro entrevistado refere que a questão da limitação da autonomia tem a ver com o RJIES, mas em menor grau, pelo que se devia, na gestão das IES, priorizar-se o RJIES em vez do OE:

[...] o que está a fazer maior mossa na autonomia são as normas de âmbito geral, como qualquer norma é de âmbito geral... são as normas do $\mathrm{OE}$, aplicáveis a quem tem e a quem não tem autonomia e que, para quem tem autonomia, acaba, não pela via direta mas pela via indireta, por restringir a autonomia [...] (F14, 2014).

Para além disso, no contexto de contenção económica que o país estava a viver, por vezes ocorreram situações inesperadas nos orçamentos, 
A autonomia do Ensino Superior Português entre a lei e a prática - estudo de caso múltiplo

[...] como aconteceu este ano [2013], a meio deste ano disseram-me o seu orçamento para a segurança, para a vigilância está cativado... É difícil gerir sem saber com o que se pode contar... a capacidade de planeamento está muito comprometida e isto de ser autónomo sem poder planear [...] (F9, 2013).

\section{Especificidades do setor politécnico}

RJIES retirou a autonomia financeira às unidades orgânicas dos Institutos Superiores Politécnicos. Existe assim uma centralização da autonomia no Instituto Superior Politécnico em detrimento das Escolas Superiores que o compõem.

Em relação a esta questão, os entrevistados consideram que esta autonomia centralizada na Presidência do Instituto facilita muitas coisas em termos de gestão e concordam com a situação, na medida em que dentro do ISP, as escolas agregadas são mais fortes do que uma escola isolada e também porque a autonomia financeira implica uma maior responsabilização que, em tempo de crise, permite uma melhor gestão a nível central. Assim, orçamento atribuído

[...] está cabimentado e se nós gerirmos as coisas de maneira correta, está normalmente assegurado, temos autonomia para autorizar despesas até 5000 euros, o que significa que a vida corrente da escola se processa normalmente [...] (IP3, 2014).

espírito de abertura das presidências em relação às iniciativas pedidas pelas escolas do ISP, também é referido como um elemento importante nesta transição. De acordo com os entrevistados, as propostas apresentadas pelas escolas têm uma boa receção por parte da presidência. Outro elemento apontado como uma vantagem é a racionalização de recursos humanos e materiais que adveio desta nova organização, pois como refere,

[...] acho que faz sentido não terem autonomia e os serviços estarem [...] centralizados (na presidência) porque as escolas não têm knowhow para fazer bem feito, ou seja, as escolas não sabem contabilidade como aqui podemos saber, não sabem comprar como aqui podemos comprar [...] mas eles têm alguma autonomia, têm 
autonomia administrativa [...]. Acho que devíamos centralizar mais ainda [...] (IP14, 2013).

Deste modo, da forma como as coisas se passam, quando alguma escola tem dificuldades económicas, todas as escolas participam e ajudam, sendo solidárias, assumindo-se como mecenas das escolas necessitadas.

É neste quadro que as Escolas Superiores, através dos seus dirigentes, não sentem ter perdido competências de âmbito financeiro em consequência do RJIES.

\section{Considerações finais}

conceito de autonomia pode ter várias interpretações de acordo com o contexto histórico, cultural, económico e político de um país. Uma vez que não existe autonomia no estado puro, concetual, pois a universidade não é um elemento isolado, pertence a uma sociedade e, apesar ser reconhecida a necessidade de autonomia para um saudável funcionamento de uma instituição de ensino superior, há a consciência, atualmente, da necessidade de responsabilização, de accountability das universidades perante os parceiros que, crescentemente, vão sendo envolvidos na vida da academia. No caso português, torna-se evidente nas leis e nas práticas, a configuração ampliada desta nova conceção, desta nova relação.

No caso português, a autonomia estabelecida por lei, no RJIES, encontra-se limitada por outras leis, principalmente a lei dos compromissos, Lei n. ${ }^{\circ}$ 22, de 17 de março de 2015, que estabelece que (art. 9, pagamentos),

Nenhum pagamento pode ser realizado, incluindo os relativos a despesas com pessoal e outras despesas com caráter permanente, sem que o respetivo compromisso tenha sido assumido em conformidade com as regras e procedimentos previstos na presente lei e em cumprimento dos demais requisitos legais de execução de despesas (PORTUGAL, 2015).

facto de o país se encontrar numa situação de crise económica e social faz com que as leis de execução orçamental, com a tónica na contenção e na redução da despesa, se imponham sobre todas as leis, revogando na prática as autonomias concedidas. Esta lei pressupõe que uma IES sabe à 
A autonomia do Ensino Superior Português entre a lei e a prática - estudo de caso múltiplo

partida todos os gastos, todas as despesas que precisa de efetuar, retirando a capacidade de planeamento que parece, na universidade, afetar a gestão de médio prazo, mas nos politécnicos afeta a gestão a curto prazo, numa base diária.

Oensino superior público português, neste momento e de acordo com os entrevistados tem muito pouca autonomia, principalmente o subsistema do ensino superior politécnico. Em termos de autonomia financeira, é referido na lei que as IES são livres de aplicar os fundos de receitas próprias como entendem, mas, na realidade, neste momento e como descrito, o estado tem ingerência na aplicação destes fundos porque por causa da execução, as despesas têm que ser todas cabimentadas antes de serem efetuadas. Por outro lado, esta situação de cabimentação aplica-se também ás despesas dos projetos de investigação. Geralmente os projetos de investigação são orçamentos bianuais ou plurianuais e existem entidades financiadoras que só pagam mediante a apresentação de despesa. Ora, esta situação não se coaduna, como referem os entrevistados com um orçamento anual, que é passível de ser cativado ao longo do ano.

A nível de autonomia administrativa, as IES estão limitadas em termos de contratação de pessoal, uma vez que podem contratar desde que não aumente a despesa e têm que recorrer à bolsa de mobilidade da função pública, onde muitas vezes não existem os perfis requeridos pelas IES, por uma questão da politica de mobilidade da função pública do governo. Por outro lado, conferencistas, docentes a curto prazo, visitantes, convidados, estão ao abrigo do mesmo quadro legal, o que pode afastar algumas personalidades que não queiram submeter-se aos procedimentos burocráticos de contratação.

Pelo quadro descrito pela maioria dos entrevistados, a autonomia no ensino superior está fortemente limitada em todas as dimensões, com exceção da científica. Assim, e apesar das críticas formuladas per uma boa parte dos entrevistados deve registar-se que foi referida com muito agrado a garantia da liberdade académica por todos reconhecida e que aproxima o ensino superior português dos sistemas de ensino superior da generalidade dos países desenvolvidos, mormente os dos nossos parceiros europeus lamentando-se, todavia, as limitações que sofre hoje a "autonomia universitária" facto a que não é estranho o subfinanciamento crónico do ensino superior Português desde os finais do século passado e a necessidade de as IES procurarem receitas compensadoras no exterior. 


\section{Nota}

1 presente artigo decorre da investigação em curso no âmbito de doutoramento em Educação, realizado no Instituto de Educação da Universidade de Lisboa, intitulada "Financiamento do ensino superior público português: diversificação de fontes" (bolsa de doutoramento atribuída pela FCT - Fundação para a Ciência e Tecnologia, com a referência SFRH/BD/84398/20121.

\section{Referencias}

AMARAL, Alberto; Magalhães, António. $\bigcirc$ conceito de stakeholder e o novo paradigma do ensino superior. Revista Portuguesa de Educação, Minho, v. 13, n. 2, p. 7-28, 2000.

ALTBACH, Philip. Academic freedom: International realities and challenges. Higher Education, Netherlands, v. 41 , p. 205-219, 2001.

BARDIN, Laurence. Análise de conteúdo. Lisboa: Edições Setenta, 1977.

BERDHAL, Robert. Academic freedom, autonomy and accountability in British universities. Studies in Higher Education, v. 15, n. 2, p. 169-180, 1990.

BOGDAN, Robert; BIKLEN, Sari. Investigação qualitativa em educação. Porto: Porto Editora, 1994.

CABRITO, Belmiro Gil. Análise socioeconómica do financiamento do ensino superior Universitário em Portugal: contributos para o processo decisional de (re)construção de uma política sócio-educativa para o ensino superior universitário público. 1999. Tese (Doutorado em Educação) - Faculdade de Psicologia e de Ciências da Educação, Universidade de Lisboa, Lisboa, 1999.

Financiamento do ensino superior. Lisboa: Educa, 2002.

CERDEIRA, Luísa. O financiamento do ensino superior português. A partilha de custos. Coimbra: Almedina, 2009

CHRISTENSEN, Tom. University governance reforms: potential problems of more autonomy? Higher Education, v. 62, p. 503-517, 2011.

DURHAM, Eunice. A autonomia universitária: extensão e limites. São Paulo: NUPES/USP, 2005. Disponível em: http://nupps.usp.br/downloads/docs/dt0503.pdf. Acesso em: out. 2016.

F2. Entrevista. Lisboa (Portugal), 13 nov. 2015. 
F5. Entrevista. Lisboa (Portugal), 3 out. 2013.

F7. Entrevista. Lisboa (Portugal), 12 mar. 2014.

F9. Entrevista. Lisboa (Portugal), 24 out. 2013.

F10. Entrevista. Lisboa (Portugall), 20 maio 2014.

F12. Entrevista. Lisboa (Portugal), 28 nov. 2013.

F14. Entrevista. Lisboa (Portugal), 25 mar. 2014.

F15. Entrevista. Lisboa (Portugal), 26 nov. 2015.

FROELICH, Karen. Diversification of revenue strategies: evolving resource dependence in nonprofit organizations. Nonprofit and Voluntary Sector Quarterly, v. 28, p. 246-268, 1999.

FUCHS, Robert. Academic Freedom - Its Basic Philosophy, Function, and History. Articles by Maurer Faculty. Paper 1634, 1963. hitp://www.repository.law.indiana.edu/ facpub/1634. Acesso em: 13 out. 2015

GIBB, Allan; HASKINS, Gay; ROBERTSON, lan. Leading the entrepreneurial university: meeting the entrepreneurial development needs of higher education institutions. In: ALTMANN,

70 Andreas; EBERSBERGER, Bernd (Ed.). Universities in change, innovation, technology, and knowledge management (9-45). Springer Science+Business Media New York, 2013.

GOMES, José. A universidade portuguesa: perspetiva, situação e prospetiva do sistema de qualidade. Alfa-acro, Montevideu, maio 2004. Disponível em: http://www.fc.up.pt/pessoas/ifgomes/documentos/documentos/d105.pdf. Acesso em: out. 2013.

HENKEL, Mary. Academic Identity and autonomy in a changing policy environment. Higher Education, v. 49, p. 155-176, 2005.

IP1. Entrevista. Lisboa (Portugal), 9 out. 2015.

IP3. Entrevista. Lisboa (Portugal), 25 set. 2014.

IP6. Entrevista. Lisboa (Portugall), 22 maio 2014.

IP10. Entrevista. Lisboa (Portugal), 28 maio 2013.

IP1 1. Entrevista. Lisboa (Portugall), 20 fev. 2013.

IP13. Entrevista. Lisboa (Portugal), 13 mar. 2014. 
IP14. Entrevista. Lisboa (Portugal), 30 maio 2013.

JONHSTONE, Bruce. (2004) The Economics and Politics of Cost-Sharing in Higher Education: Comparative Perspectives. Disponível em: http://www.gse.buffalo.edu/org/ IntHigherEdFinance/publications.html. Acesso em: 2 jul. 2013.

KARRAN, Terrence. Academic freedom in Europe: A preliminary comparative analysis. Higher Education Policy, v. 20, n. 3, p. 289-3 13, 2007.

MORGADO, José. O Estudo de caso na investigação em Educação. Santo Tirso: Editores De Facto, 2012.

NYBOM, Thorsten. University autonomy: a matter of political rhetoric? The university in the market, the authors. Portland Press, 2008.

NYBORG, Per. Institutional Autonomy and higher education governance. In: Council of Europe Conference, Strasbourg 2-3 December 2003, Implications of the Bologna Process in South East Europe.

PORTUGAL. Decreto-Lei n 38.692, de 21 de março de 1952. Retira a autonomia administrativa às unidades orgânicas das universidades e centraliza a administração num conselho administrativo de universidade.

Decreto-Lei n 402, de 11 de agosto de 1973. Cria novas Universidade, Institutos Politécnicos e Escolas Normais Superiores, define os regimes das suas comissões instaladoras e adota providências destinadas a assegurarem o recrutamento e a formação do pessoal necessário para o início respetivas atividades. Diário do Governo, I Série, n. 188.

Lei $n^{0} 108$, de 24 de setembro de 1988. Estabelece as condições da Autonomia do Ensino Superior. Diário da República, I Série, n. 222.

Lei $n^{\circ} 46$, de 14 de outubro de 1986. Estabelece o quadro geral do sistema educativo. Diário da República, I Série, n. 237.

Lei $n^{\circ} 20$ de 14 de Agosto de 1992. Estabelece normas relativas ao sistema de propinas pela inscrição anual nos cursos das instituições de ensino superior público e o regime de isenção ou de redução de propinas de acordo com o rendimento familiar anual. Diário da República, I Série-A, n. 187.

Lei $n^{\circ}$ 62, de 10 de setembro de 2007. Estabelece o regime jurídico das instituições de ensino superior, regulando designadamente a sua constituição, atribuições e organização, o funcionamento e competência dos seus órgãos e, ainda, a tutela e fiscalização pública do Estado sobre as mesmas, no quadro da sua autonomia. Diário da República, I Série, n. 174. 
A autonomia do Ensino Superior Português entre a lei e a prática - estudo de caso múltiplo

Lei n. ${ }^{\circ}$, de 21 de fevereiro de 2012. Estabelece as regras aplicáveis à assunção de compromissos e aos pagamentos em atraso das entidades públicas. Diário da República, I Série, n. 37.

Lei n. ${ }^{\circ}$ 22, de 17 de março de 2015. Quarta alteração à Lei n. ${ }^{\circ} 8 / 2012$, de 21 de fevereiro. Aprova as regras aplicáveis à assunção de compromissos e aos pagamentos em atraso das entidades públicas. Lisboa: Ministério Público, 2015.

SANTOS, S. M. Contributos para o estudo do desenvolvimento da autonomia universitária em Portugal desde o 25 de Abril. Revista Portuguesa de Educação, v. 12, n. 1, p. 7-29, 1999.

SIMÃO, José Veiga. Modernização do ensino superior: da rutura à excelência. Lisboa: Fundação das Universidades Portuguesas, 2003.

STAKE, Robert. A arte da investigação com estudos de caso. Lisboa: Fundação Calouste Gulbenkian, 2007.

PORDATA. Alunos matriculados no ensino superior: total, por subsistema e por tipo de ensino - Portugal. Disponível em: http://www.pordata.pt/Portugal/Alunos+matriculados+n otensino+superior+total++por+subsistema+e+por+tipo+de+ensino-1019. Acesso em: jan.

722014

Mestre Ana Nascimento

Instituto de Educação da Universidade de Lisboa Unidade de Investigação e Desenvolvimento em Educação e Formação Grupo de Investigação Políticas de Educação e Formação E-mail | amarnascimento@gmail.com

Prof. Dr. Belmiro Gil Cabrito Universidade de Lisboa Instituto de Educação

Unidade de Investigação e Desenvolvimento em Educação e Formação Grupo de Investigação Políticas de Educação e Formação 
Grupo de Pesquisa Administração e Políitica Educacional, Avaliação Educacional, Formação de Adultos

E-mail | b.cabrito@ie.ulisboa.pt

Recebido $1^{\circ}$ maio 2017 Aceito 31 maio 2017 